\title{
CORRESPONDENCIA DE PEREZ BAYER, RISCO Y CORNIDE CON ANTONIO TAVIRA
}

Doble es la finalidad de estas páginas. Por una parte, dar a conocer siete cartas de Francisco Pérez Bayer a Antonio Tavira y Almazán; y por otra, publicar también dos más, complementarias de las de Bayer, dirigidas igualmente a Tavira por Fray Manuel Risco, OSA. y José Cornide. Sería ofender a los lectores de esta publicación, especializada en temas del siglo XVIII, extenderme en consideraciones previas sobre los citados personajes, figuras próceres de la ilustración española. Se impone sin embargo, para una mejor comprensión de los textos, una introducción. No se pretende un estudio exhaustivo de las cartas, sino una aclaración temática.

\section{INTRODUCCION}

Las cartas de referencia se hallan hoy en el Archivo Diocesano de Salamanca. Desgraciadamente carecen en la actualidad de catalogación y signatura. El incendio que dicho Archivo padeció hace 22 ó 23 años, además de arrebatarnos para siempre algunos de los preciosos documentos que en él se custodiaban, causó otro no menor estrago, al haberse arrojado por las ventanas del edificio los legajos en un desesperado intento de salvar lo más posible: el desorden. En efecto, buena parte de los documentos que hoy se conservan, se hallan amontonados en la más absoluta anarquía, sin que desde entonces se haya acometido la tarea de una reorganización que, al parecer, está prevista para un futuro inmediato.

Sin embargo todos los documentos que aquí se publican debieron de estar enmarcados en su tiempo en una catalogación, al menos provisional, ya que se hallan en un legajo, en el cual hay diverso material numerado todo él referido a Tavira. Nuestras cartas, junto con otro material, se agrupan en el N. ${ }^{\circ} 4$. Esta referencia numérica se halla escrita a lápiz sobre una cubierta común que dice: Cabeza del Griego. Es precisamente el cerro de tal nom- 
bre, a legua y media de Uclés, el objeto principal de esta correspondencia epistolar. De ello se hablará más tarde.

\section{Marco externo de las cartas}

Las siete cartas del erudito valenciano Pérez Bayer son todas autógrafas, así como la de Fray Manuel Risco. La de José Cornide se halla firmada y rubricada por él, aunque el texto no está copiado de su mano.

Todas las de Pérez Bayer, a excepción de la que se publica en tercer lugar, están datadas, y todas lo están en Madrid. Tan sólo esa tercera carece de data y de indicación del lugar de expedición. Tal circunstancia debió de obedecer a un olvido de su autor.

Estas cartas bayerianas abarcan desde octubre del año 1788 hasta noviembre de 1790 , y se publican por orden cronológico. ¿Por qué se ha situado la tercera, carente de toda indicación de tiempo y lugar, en dicho puesto? Porque el análisis interno del contenido así parece exigirlo. Sobre todo hay en ella una frase, referida al Sr. Vicente Martínez Falero, a quien conoceremos después, que parece determinante para la colocación de esta carta después de la carta $2{ }^{\mathrm{a}}$. En efecto, mientras en la referida carta $2 .^{a}$ promete Pérez Bayer responder a otra de don Vicente para recomendarle una vez más la guarda diligente de una piedra con su inscripción, importante para la determinación del nombre de la ciudad que existió en Cabeza del Griego, en la carta $3 .^{a}$, que continúa la temática general de la precedente (inscripciones sobre Nigrino y Sefronio, refutación de Tychsen, etc.), se afirma que ya le ha escrito. De ello se infiere que la carta sin data es posterior cronológicamente a la carta 2. ${ }^{\mathrm{a}}$. Sin embargo es anterior a la carta $4 .^{a}$, puesto que en ésta se alude a la desgraciada noticia de la pérdida de la preciada inscripción, objeto de las cartas anteriores.

Por su parte, las cartas de Risco y Cornide a Tavira son ambas de 1801; y a pesar de estar distanciadas en el tiempo 10 ó 12 años de las anteriormente reseñadas, inciden en el tema central de éstas. Para estas fechas ya había muerto Pérez Bayer y Risco estaba en las vísperas de su muerte. Tan largo lapso de tiempo entre unas y otras cartas no había hecho decrecer el interés sobre el tema de las mismas, las excavaciones en Cabeza del Griego.

Esos años transcurridos entre las cartas de Pérez Bayer y las otras dos habían traído consigo muchas mudanzas en la vida de Antonio Tavira. Tavira, que vestía el hábito de la Orden militar de Santiago, ejercía el cargo de Prior del Real Convento de Uclés en el trienio 1788-90, época de las 
cartas bayerianas. Al final de ellas se anuncia ya un cambio de rumbo en la vida de Tavira. En efecto, en la carta 6. ${ }^{a}$ de Pérez Bayer (28-X-1790) Tavira figura ya con el título de «Prior de Uclés, electo obispo de Canarias». En febrero del 91 tomaría posesión del obispado isleño, puesto que regentaría hasta el año 1796 en que pasaría a la diócesis de Osma ${ }^{1}$. De Osma pasaría Tavira en el año 1798 al obispado de Salamanca, donde murió en el año 1807. Así pues, las cartas de Pérez Bayer nos sitúan a Tavira en el priorato de Uclés, mientras que las de Risco y Cornide lo colocan en la sede salmantina.

\section{Correspondencia erudita}

La nota más característica de esta correspondencia es sin duda su carácter eminentemente erudito y científico. Salvo los in evitables ingredientes de la cortesía, muy amplificados en esta época, y el socorrido tema de la salud, se puede decir que el resto de la temática es casi exclusivamente cultural.

Con todo el tema de la salud es algo más que un tópico en la pluma de Pérez Bayer: y es que el valenciano, no lo olvidemos, anda ya rozando los ochenta de edad, por lo que sus achaques adquieren paulatinamente caracteres preocupantes. Se nos informa que en diciembre del 89 se halla convaleciente «de cinco semanas de cama con vehementes dolores de riñones y estómago y una destilación fuerte al pecho, que se temió degenerase en pulmonía». Consiguientemente añade: «Estoi débil, la cabeza como hueca», por lo que apenas puede trabajar en dar los últimos retoques a la obra que trae entre manos sobre las monedas en refuración de Oluf Gerhard Tychsen (1734-1815)². En abril del 90, aún sintiéndose bien en su estado general, acusa flojera de piernas, por lo que añade con fino humor e interesante dato costumbrista: «Pienso hacer por las mañanas unas saliditas y dar algún passo ayudado de un bastón (pues veo que también lo llevan los jóvenes y aún los niños por moda, y assí no me costará vergüenza)». Sin embargo la caligrafía de Pérez Bayer se conserva, a pesar de todo, segura y

1 En el mismo Archivo diocesano de Salamanca, aunque en otros legajos, tampoco catalogados, se conserva también diverso material referido a Tavira del tiempo de estos dos obispados, material que no ha sido estudiado hasta el presente. Merece especial mención un nutrido fajo de cartas y apuntes autógrafos.

2 Se trata de Nummorum Hebraeo-Samaritanorum Vindiciae (Valencia 1790). Bayer la nombra en estas cartas de diversas maneras: De numis Hebr. Samar. adversus Tychsenium (carta 2. ${ }^{a}$ ); Auctario (carta 4. ${ }^{\mathrm{a}}$ ); Auctario o Vindicias (carta 5. ${ }^{\mathrm{a}}$ ); Vindicias numor. Hebr. Samaritanor. contra Tychsen y otros (carta $\left.6 .{ }^{a}\right)$. 
hasta elegante ${ }^{3}$. Se cuida especialmente de los fríos: por eso no ha ido a casa de don Pedro, hermano de Tavira, a transmitirle la enhorabuena por la elección de su hermano a la mitra de Canarias y espera la licencia real para pasar lo recio del invierno en su país valenciano, de clima más benigno que Madrid para sus casi ochenta años.

Son frecuentes las referencias a la aludida obra bayeriana sobre las monedas, hasta el punto de poderse seguir perfectamente a través de estas cartas el proceso final de su elaboración. En el tiempo de la convalecencia de las cinco semanas de cama está ya, según dice, «limando» la obra. Y un dato interesante. "Va a imprimirse - le dice a Tavira- y se dedicará a nuestra común madre la Vniversidad de Salamanca» (carta 2.a ${ }^{4}$. Con todo acabó dedicándose al rey Carlos IV, como el primer escrito del tema ${ }^{5}$ se dedicó a su padre Carlos III.

La razón del cambio de dedicatoria, tal como se explica en la carta $5 .^{a}$, caso de corresponder a la verdad, fue que inicialmente pensó que el escrito iba a ser un pequeño folleto. Pero al haberse convertido en un respetable tomo con entidad propia, se creyó obligado a dedicarlo al monarca, al igual que hiciera con el primer tomo ${ }^{6}$. La obra se imprimió en el transcurso del año 1790. En octubre estaba ya encuadernándose el volumen, que ostentaba al principio el Real retrato. En la primera decena de noviembre ya pudo presentarse el libro al Rey en el Real Sitio de Aranjuez. Bayer promete enviar un ejemplar a don Pedro y, naturalmente, otro al obispo electo de Canarias para que, dejando aparte el afecto, le dé su parecer.

La pluma de Pérez Bayer rezuma a las veces una gran agresividad y desprecio contra su contrincante ideológico, Tychsen, de quien no duda en repetir que no entiende absolutamente nada del tema y a quien llama «un gran canalla».

3 Quizá el pulso vacilante, o simplemente una distracción, hizo caer un grueso borrón en una parte del pliego de la carta 5.". Añade Bayer, a la vera de la mancha: «Esto es el si quid humanitus. Perdónelo VM.m.

4 Sobre las relaciones de Tavira y Bayer con la Universidad de Salamanca, Leopoldo Juan Garcta, Pérez Bayer y Salamanca. Datos para la bio-bibliografía del hebraista valen. ciano (Salamanca 1918); Joël SaugnieuX, Un prélat eclairé: Don Antonio Tavira y Almazán (1737-1807). Contribution à l'étude du jansénisme espagnol (Toulouse 1970) 24-26.

5 De nummis Hebraeo-Samaritanis (Valencia 1781).

6 La razón aducida por Pérez Bayer causa la impresión de ser un titulus coloratus, ya que la intención primera la expresa tan sólo unos meses antes, cuando ya estaba dando los últimos retoques a la redacción definitiva. Debieron de intervenir, por lo tanto, otros factores distintos de los que transparenta la pluma de Bayer. 
Otras noticias culturales de interés son además sus trabajos sobre Nicolás Antonio ${ }^{7}$, sobre el envío de varios cajones de libros para la biblioteca de Valencia ${ }^{8}$, sobre las retractaciones de monsieur Barthelemy, primer anticuario del rey de Francia, que le ha dado la razón sobre la identidad de ciertas monedas antiguas y sobre la interpretación de una famosa inscripción fenicia de Malta.

\section{Los descubrimientos arqueológicos de Cabeza del Griego}

Todos los anteriores temas eruditos, con ser importantes, no constituyen sin embargo el objeto principal de estas cartas de Bayer a Tavira. El tema central lo acaparan los descubrimientos de las ruinas arqueológicas del cerro llamado Cabeza del Griego, cercano al Real Convento de Uclés, donde mora Tavira. Estos importantes descubrimientos apasionaron durante mucho tiempo a los estudiosos de nuestra Historia y de nuestra Geografía. Imposible resultaría dar cuenta de esta interminable y apasionada discusión que duró siglos ${ }^{9}$. De lo que no cabe duda es de que fueron los descubrimien-

7 Se trata de la gran obra, publicada a finales de ese año, Bibliotheca Hispana Vetus... auctore. D. Nicolao Antonio, curante Francisco Perezio Bayerio... 2 vols. (Madrid 1788). El pasaje del Prólogo a que alude la carta $1 .^{a}$ dice: "Anonymos scriptores Nicolao Antonio indictos, niśi quos patria, dignitatis aut honorum gradus, peculiarisve scriptionis indoles aut tale aliquid velut intento digito designat, parum moratus sum» (Ibíd. I, p. XI).

8 Como es sabido, Pérez Bayer donó su rica biblioteca de erudito -unos 20.000 volúmenes- a la Universidad de Valencia.

9 Puede decirse que la discusión se prolonga desde Ambrosio de Morales hasta hoy. Como anotan muy bien Masdeu y Madoz, sobre este tema gravitaron otras motivaciones distintas de las estrictamente científicas, ya de por sí complicadas: intereses regionales entre valencianos, toledanos y aragoneses, ambiciones jurisdiccionales eclesiásticas, etc.: Cf. Juan Francisco Masdeu, Historia crítica de España y de la cultura española XVII (Madrid 1797) 321-22; Pascual MADoz, Diccionario geográfico-estadístico-histórico de España V (Madrid 1846) 27. Véase también la voz Segóbriga en el t. XIV (Madrid 1849) 64-67. La bibliografía fundamental de la discusión y sus diferentes fases las da con gran competencia Emilius HuEBNER-, Inscriptiones Hispaniae Latinae, en Corpvs Inscriptionvm Latinarum II (Berolini 1869) 419-25. En las páginas 419-20 un estupendo estudio introductorio con la bibliografía fundamental, y a partir de la página 420 las inscripciones de Cabeza del Griego, Uclés y Sahelices, que comprenden desde el n. 3090 hasta el n. 3164. Entre los estudios posteriores a Hübner, citaré tan solo dos importantes, entre la abundante literatura que siguió produciendo Cabeza del Griego: 1.") Juan de Dios DE LA RADA-Fidel FITA, "Excursión arqueológica a las ruinas de Cabeza del Griego", Boletín de la Real Academia de la Historia XV (Madrid 1889) 107-51. De este artículo merece especial mención el códice titulado Diligencias de la excavación de Sahelices, que es una copia del proceso canónico instruido por el obispo de Cuenca sobre el tema en 1790-92. De él se da cuenta en las pp. 114-115. Resalto este códice porque en el legajo de nuestras cartas se contiene una parte de él: las deposiciones ante el juez comisionado, Dr. 
tos patrocinados por Tavira los que más elementos de juicio aportaron y los que con más fuerza avivaron una discusión que ya venía de atrás.

Pero aunque no es este el lugar de analizar a fondo un tema excesivamente técnico y fuera del marco de este estudio, es necesario sin embargo aportar algunos datos que ayuden a valorar las cartas aquí publicadas. Cuando Tavira llegó a Uclés y tuvo noticia de que en el pasado año 1760 se habían encontrado en el famoso cerro unos restos arqueológicos con inscripciones, decidió, coaligado con otras personas influyentes, promover nuevamente unas excavaciones más serias. Esta especie de sociedad arqueológica la formaban por una parte el propio Prior de Uclés, bajo cuya jurisdicción caía el cerro en cuestión, quien costearía la mitad del gasto de los trabajos, y por otra don Vicente Martínez Falero, «alcalde por el estado noble» de Saelices, en cuyo término radicaba Cabeza del Griego, y don Bernardo Manuel de Cosío, cura de la parroquial de Saelices, quienes correrían con la otra mitad de los gastos. De don Vicente dice el propio Tavira en carta al conde de Floridablanca, cuya copia se conserva en el mismo legajo que nuestras cartas, que era «por el estado noble sugeto hacendado y muy zeloso del bien público» ${ }^{10}$.

También colaboraron de una manera muy directa en la empresa don Juan Francisco Martínez Falero, sobrino de don Vicente, «abogado de mucha y buena instrucción y particular mérito», como dice Tavira en la ya

Roque Ballesteros Alamanzón, de Bernardo Manuel de Cosío (23-III-1790) y Juan Francisco Martínez Falero (6-X-1790). En el legajo se halla también la minuta autógrafa de una carta de Tavira al juez Ballesteros que trata del referido proceso canónico. Es de fecha desconocida, pero contesta a otra de Ballesteros del 18-XI-1790. $2 .^{\circ}$ ) Aureliano Fernández-Guerra y Orbe, 'Una tésera celtibérica. Datos sobre las ciudades celtibéricas de Ergávica, Munda, Cértima y contrebia", Boletín de La Academia de la Historia I (Madrid 1909), pp. 129-39.

La posición de hoy día puede verse en Historia de España, dirigida por Ramón MENÉndeZ Pidal, t. II (Madrid 1935) 77, 125-29, 216 t. III (Madrid 1940) 278, 292-96. Por estas citas puede comprobarse cómo la crítica histórica está hoy del lado de la opinión defendida por Pérez Bayer en las cartas publicadas en este estudio, que no es otra que en Cabeza del Griego estuvo emplazada la ciudad de Segóbriga y que los obispos Nigrino y Sefronjo fueron obispos segobricenses. Con todo, es curiosa la manera cómo se menciona a Ergávica, la otra gran pretendiente a ocupar el puesto.

En estas páginas tan sólo se hará mención de aquellas posiciones que tengan que ver con las personas relacionadas con nuestros personajes.

10 Carta del 14-XII-1789. La minuta de esta carta se conserva, como queda dicho, en el Archivo diocesano de Salamanca. El original manuscrito se conservá en la Real Academia de la Historia (11-1-3-8009-4):cf. Joël SaUgnieux, o. c. 93. 
citada carta al conde de Floridablanca ${ }^{11}$ y Juan Antonio Fernández, notario eclesiástico y archivero del Sr. Obispo de Tudela, quien actúa en calidad de notario en las actas de los descubrimientos, copia las inscripciones, ejecuta dibujos, levanta planos y nos deja varias memorias de los hallazgos ${ }^{12}$. Juan Antonio había sido llamado a Uclés por Tavira para proceder a la organización del riquísimo Archivo de la Orden de Santiago que se albergaba en aquel Real Convento, al decir de Tavira «uno de los mayores del Reyno». De los trabajos de don Juan Francisco se hablará al hacerlo de la carta de Cornide a Tavira.

Las excavaciones en el cerro se iniciaron el $17-\mathrm{X}-1789$, por lo que, lógicamente, la primera carta de Pérez Bayer de fecha 28 del mismo mes nada dice todavía sobre el particular. Pero los trabajos de excavación empezaron inmediatamente a arrojar sorprendentes resultados que Tavira comunica puntualmente de una manera confidencial a su amigo Pérez Bayer y de una manera oficial al conde de Floridablanca. El primer día clave de las excavaciones es sin duda el 14-XII-1789, cuando se descubren los sepulcros con los restos de los obispos Nigrino y Sefronio ${ }^{13}$. En las lápidas que formaban altar sobre sus sepulcros estaba esculpida esta inscripción:

\section{+ HIC SVNT SEPVLCRA SANCTORUM

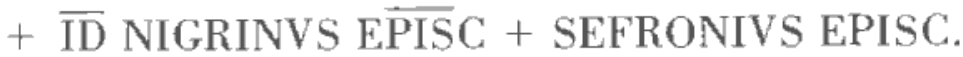

Ese mismo día envía Tavira una memoria pormenorizada al conde de Floridablanca, con dibujos y explicaciones, pidiéndole haga llegarlo todo a Su Majestad ${ }^{14}$. El conde contesta el 28-I-1790 ${ }^{15}$. El rey, como se dice en

11 Don Juan Francisco aparece en su deposición del 6-X-1790 (cf. nota 9) como «Sr. licenciado, abogado de los Reales Consejos y Alcalde ordinario por S. M. y estado noble de Saelices». A finales del 89 era alcalde su tío Vicente.

12 Estas memorias se conservan también en la Real Academia de la Historia: cf. E. Huebner, o. c. 420 y'Joël SaugnieuX, o. c. 92 . Hübner considera los trabajos de Juàn Antonio más valiosos que los de Palomares, Capistrano de Moya y nuestro Cornide.

13 El acta de la invención en Menorias de la Real Academia de la Historia III (Madrid 1799) 235-39. Sin duda la tomó Cornide, que es el autor del trabajo sobre Cabeza del Griego publicado en ese tomo de las Memorias de la Real Academia, de los trabajos de Juan Antonio Fernández citados en la nota 12 , donde se inserta.

14 Los dibujos eran obra del repetidamente citado Juan Antonio Fernández. Los que eran en concreto los reseña Joël SaUgnievX, o. c. 93.

15 El texto de esta respuesta de Floridablanca lo publica Cornide en Memorias... 242. Sin duda lo tomó también de los trabajos de Juan Antonio Fernández. El original de esta carta de Floridablanca se halla en el mismo legajo de las cartas que publicamos del Archivo diocesano de Salamanca. El texto publicado es totalmente fiel al original. 
esta respuesta de la corte, había decidido pasar el asunto a la Real Academia de la Historia. Esta, a su vez, emitió un primer informe el día 12-XI1790 por medio de los académicos José Guevara y José Cornide, el autor de nuestra carta a Tavira.

La primera carta de Tavira a Pérez Bayer, comunicándole el hallazgo de los sepulcros de Nigrino y Sefronio, se escribió el día 16-XII-1789, o sea dos días después del descubrimiento y de la noticia enviada al conde de Floridablanca. De ahí que Bayer, según se dice en la respuesta del día 18 de ese mismo mes, abrigue la esperanza de que «el señor conde de Floridablanca me hará saber algo de lo que VM. me escribe». Ignoramos si lo hizo.

Pero Bayer, aún estimando sobremanera el hallazgo de los sepulcros de los dos obispos, apunta ya desde el primer momento con gran visión del punto central que había que dilucidar, al auténtico nudo gordiano: la identidad de la ciudad que un día estuviera emplazada en Cabeza del Griego. Su intuición y su deseo se orientan hacia la importe metrópoli de Segóbriga: «Bueno fuera - dice- se hallase el nombre de Segobrica: pero para mí está ya bastantemente descubierto en la piedra de casa del Sr. D. Vicente Martínez [Falero] en el pedacito más chico de los tres de que consta, el qual debe guardarse como oro". Por los breves datos antes adelantados, ya conocemos a la persona que nombra aquí Pérez Bayer.

En la siguiente carta, la carente de fecha y lugar, pero que puede fecharse en los últimos días del año 1789, entra en escena el agustino Fray Manuel Risco, conocido especialmente en el ámbito de la cultura como continuador de la España Sagrada de Enrique Flórez ${ }^{16}$. Pérez Bayer confía al agustino todo el material que le había sido remitido por Tavira, fiado sin duda en el buen criterio del famoso historiador. La misma confianza en Risco se observa en la carta $4 .^{\mathrm{a}}$, donde escribe nuevamente el valenciano: «Todo lo verá el P. M. Risco». Sin embargo, en la discusión subsiguiente sobre el tema, Pérez Bayer y Risco defendieron las dos posturas antagónicas sobre Cabeza del Griego. Mientras para el primero no ofrecía ninguna duda de que en el famoso cerro estuvo ubicada la antigua ciudad romana de

16 A la muerte de Flórez (1773) fue nombrado Risco su sucesor en la España Sagrada con los mismos privilegios, exenciones y pensión real que su antecesor. Comenzó publicando los tomos XXVIII-XXIX que quedaron inconclusos a la muerte de Flórez, continuando después la serie hasta un total de 13 tomos. 
Segóbriga ${ }^{17}$, Risco defenderá con pasión que allí se ubicó la ciudad romana de Munda de que habla Tito Livio en el cap. 47 del libro $40^{18}$.

A lo que conozco, Pérez Bayer no dio a la publicidad ningún escrito sobre los descubrimientos arqueológicos de Cabeza del Griego -tanto más valor tienen estas cartas a Tavira-. Me confirma en ello el que Risco, en el escrito citado hace un momento en la nota 18 , se refiere tan sólo a que en el pasaje referido en la nota 17 de la carta publicada en la Historia general de Mariana, «por lo mismo reputa [Bayer] a Segóbriga que a Cabeza del Griego» (p. 333), sin mencionar ningún otro escrito ni argumento de Bayer sobre el tema. Da la impresión que para Bayer se había llegado efectivamente a una evidencia tal en el tema, que no había por qué acumular discursos ni argumentos.

Uno se pregunta de dónde había extraído Bayer esta evidencia. Quizá a ello puedan ayudarnos nuestras cartas. Ya se ha visto cómo para él era claro desde el principio, por la piedra conservada por don Vicente Martínez Falero, la ubicación de Segóbriga en el cerro manchego. Sin embargo todo su interés radicaba en confirmar aquella especie de intuición -más del corazón que de la cabeza- fundada en unas letras inscritas en una piedra: la confirmación sería dar con el nombre completo de Segóbriga, del que pudieran formar parte aquellas letras de la piedra de don Vicente.

Años atrás había estado Bayer en Cabeza del Griego, donde vio la famosa piedra encontrada en el cerro y que conservaba don Vicente. El más pequeño de los trozos parecía contener unas letras pertenecientes a la palabra mágica buscada. Entonces Bayer lo copió, pero ahora no encuentra su transcripción entre sus papeles: cree recordar que se trataba de las letras COBR (carta $3 .^{\mathrm{a}}$ ) o bien de las letras OBR (carta 4. ${ }^{\mathrm{a}}$ ). ¿Cómo casar aquellas

17 En los Apéndices al tomo 9. de la Historia general de Mariana de la edición de Valencia se publica una «Carta del Il, tro Señor D. Francisco Pérez Bayer que sirve de ilustración al lugar de Mariana Tom. 1. Lib. III. Cap. XX. p. 293»: Historia general de España que escribió el P. Juan de Mariana... (Valencia 1796) CLIII-CLXIV. Pues bien, en la pág. CLVII leemos: «... Segóbriga o Cabeza del Griego despoblado en la Mancha alta a legua y media de Uclés». Esta carta de Bayer está fechada en Madrid a 21 de marzo de 1792, es decir unos dos años largos después de la correspondencia con Tavira que aquí se publica. Cuando se publicó en la Historia de Mariana, su autor ya había muerto.

18 Cf. "Demostración de la existencia de dos ciudades llamadas Munda y Certima en tiempo de los Romanos...": España Sagrada, por el P. M. Fr. Manuel Risco. tomo XLII (Madrid 1801) 331-54. Este mismo escrito de Risco, como dice Cornide en la carta a Tavira que publicamos, se publicó anteriormente en «la Gaceta». No he podido localizar esta publicación anterior. 
letras con las nuevas inscripciones que le ha enviado Tavira? Por una parte aventura la hipótesis de que sean las mismas letras 'OBI del texto que le ha enviado su corresponsal, aunque en la postdata de la carta añade que «seguramente las letras OBI... no pertenecen a SEGOBRICA, cuya voz no cabe en el verso». De ahí que, apoyado en otra transcripción un tanto variante de la de Tavira enviada por Falero (don Juan Francisco) que dice NO SOBI, aventura tímidamente que pueda tratarse de la lectura Nos obitus.

Las observaciones epigráficas que jalonan toda la carta $4 .^{\mathrm{a}}$ de Bayer resultarán sin duda ininteligibles para el lector, al desconocer éste los textos a que aluden. Por eso, ninguna mejor aclaración a este texto bayeriano que transcribirlos aquí. Se trata de unos dísticos que cantan las virtudes del obispo Sefronio, cuyos restos vimos se habían descubierto en Cabeza del Griego el día 14-XII-1789 junto con los del obispo Nigrino. Parte de esos versos se encontraron felizmente el día 4-[-1790, que fue el segundo día clave de las excavaciones. Las deposiciones en el proceso canónico de don Bernardo Manuel de Cosío y de don Juan Francisco Martínez Falero (cf. nota 9) narran con detalle el acontecimiento: al descombrar un recinto o edícula de la basílica enterrada en el cerro manchego, salen a luz tres trozos de una lápida de mármol con inscripciones referidas a Sefronio. Al ver el mármol y sus inscripciones todos los presentes se dan cuenta inmediatamente, por sus características, que pertenecen a la misma lápida de la que se habían encontrado hacía bastantes años otros tres trozos y que conservaba en Saelices don Vicente Martínez Falero. A estos últimos, en especial al más pequeño, es a los que alude reiteradamente nuestra correspondencia de Bayer como probables pistas para localizar la palabra Segóbriga. Se apresuran a traerlos de Saelices para comprobar la coincidencia, que es total. Compuestos los seis trozos, queda bastante íntegra la inscripción. Faltaban, sin embargo, algunos datos importantes, como la fecha y parte de algún verso, que se completaron posteriormente (aunque ya se habían descubierto también, cosa de que nadie se percató en aquel momento) ${ }^{19}$.

19 Fernández-Guerra (cf. nota 9) da noticia detallada de los distintos fragmentos en que se hallaba partida la lápida sepulcral con el canto a las virtudes de Sefronio y de la suerte de cada uno: «Nueve pedazos había sido hecha su lápida sepulcral: uno pareció en 1760 y vino a parar a cierta cuadra de labor de Montalbo; dos en 1768, que con el anterior se trajeron a Sahelices; y tres cuando las valientes excavaciones llevadas a cabo desde octubre de 1789 a junio de 1790. Otros dos, muy importantes por contener la fecha y completar algunos versus difíciles, se trasladaron a Montalbo en 1771. Es singular que de ellos no se acordase la Academia, al publicar lindamente grabados los seis primeros, en el tercer tomo de sus 
He aquí los versos, tal como se habían logrado leer antes del 10-III1791, según se transcriben en el folleto ilustrado a que se hace referencia en la nota:

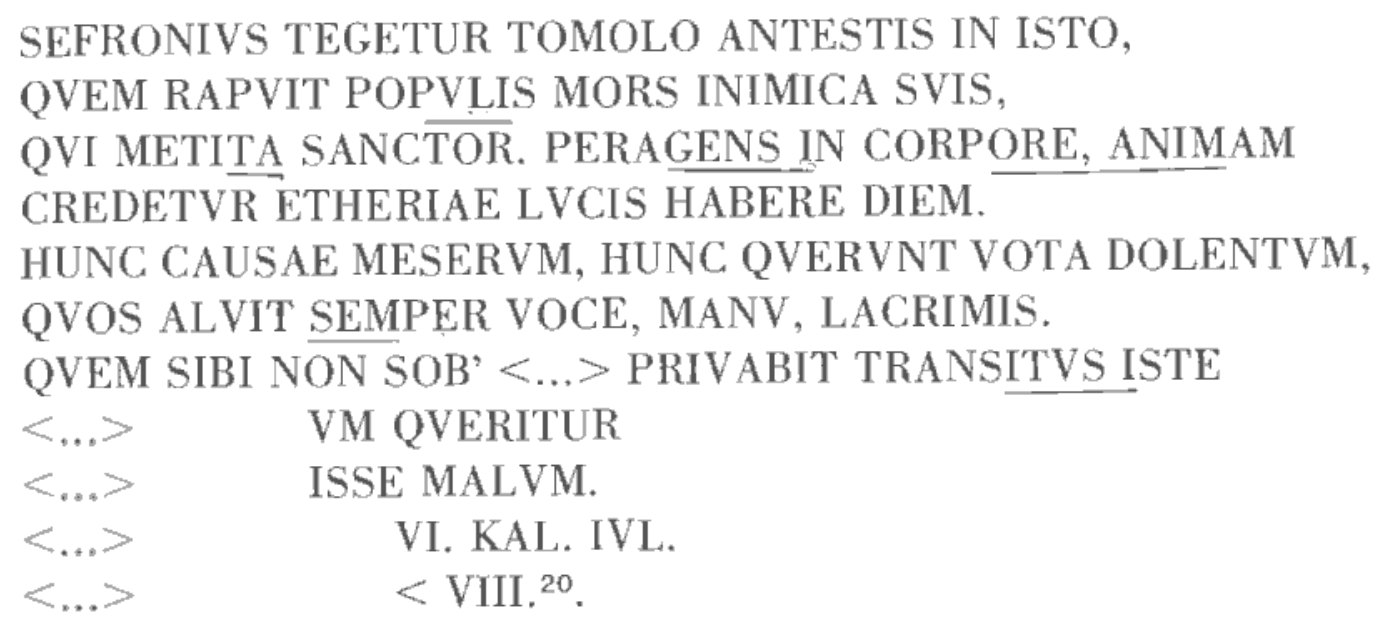

Si el día 4 de enero salían a la luz del día los trozos de mármol con parte de esta inscripción, el día 6 se apresura Tavira a enviarle copia a su amigo

Memorias, año de 1799; y eso que en 1792 y en 1795 había salido a luz íntegra la inscripción funeraria: en papeles sueltos, por D. Vicente y D. Juan Francisco Falero; y en folletos, por D. Jácome Capistrano de Moya” (o. c. 139).

20 La transcripción que ofrezco en el texto está tomada de un elegante folleto hecho a mano, y conservado en el mismo legajo de nuestras cartas, que tiene el siguiente título: + COLECCION / de los / MONUMENTOS / que ha producido la Excavación practica/da en el cerro de la Caveza del Griego en el término de Sahelizes, hasta oy 10. de/Marzo, año de 1791». Este folleto es un conjunto de láminas, hechas con técnica de acuarela y de notable calidad pictórica, donde se levantan planos, se hacen dibujos de objetos y se transcriben inscripciones de todo lo relativo a las excavaciones. Las láminas de este elegante folleto están firmadas de la siguiente manera: «Thom. Fiñz. et Salazar fec. Uclensis. Por José Cornide sabemos que este Tomás Fernández era el boticario de Saelices. Y por lo que dice este autor, debió de tener entre las manos el folleto con las láminas del boticario: «En este estado se quedaron las ruinas de Cabeza del griego hasta que el zelo del Señor Tavira y... las pusieron de manifiesto, comunicándonos exactas copias de las inscripciones y demás antigüedades descubiertas, formadas con esmero y conocimiento por Don Juan Antonio Fernández (que a la sazón se hallaba en Uclés arreglando aquel archivo), y por Don Tomás Fernández, boticario en aquella villa bastante inteligente en el dibuxo, como lo he reconocido por la confrontación de los que antes de ahora se habían remitido a la Academia con los originales existentes en aquel terreno»: "Noticia de las antigüedades de Cabeza del Griego, reconocidas de orden de la Real Academia de la Historia por su académico de número don José Cornide", Memorias de la Real Academia de la Historia III (Madrid 1799) 212. A mí no me cabe duda de que Cornide está refiriéndose al folleto del Archivo diocesano de Salamanca y que entonces estaría en poder de Tavira, o a una réplica del mismo. Considero incluso probable que las ilustraciones del trabajo de Cornide deben mucho a los dibujos de Tomás Fernández. Más aún: el dibujo publicado en la 
Bayer. Por aquellos días todavía había dudas en la lectura de algunas cosas, tanto más cuanto que faltaban tres pedazos de mármol. Lo pertinente de las observaciones de Bayer aparece claro del cotejo entre la inscripción y la carta $4 .^{a}$. Mucho se podría decir de cada cosa. Yo me limito a alguna observación: en primer lugar puede decirse que la segunda parte del hexámetro QVI MERITA... es prácticamente la lectura de la carta de Bayer. Es más, la lectura de la palabra animam, más incorrecta desde el punto de vista métrico, queda relegada posteriormente para volver a la palabra vitam propuesta por Bayer. En segundo lugar también se acepta el non sobito (=us) bayeriano. En cuanto al VIII. final, Bayer fue también en lo cierto al indicar que era el final de la era, pero fue más cuanto que Juan Fco. Martínez Falero y los demás que leyeron una $C$ antes de dicho número, creyendo que los dos trazos que aparecían en el mármol eran los bordes de esta letra, cuando en realidad, como el mismo Juan Fco. constataría, eran los bordes de una X, ya que la muerte de Sefronio, de la que se hablaba en la parte final de la inscripción, acaeció «a diez y seis de las calendas de julio de la era quinientos ochenta y ocho» (D.LXXXVIII) ${ }^{21}$.

El pesimismo observado en la carta $4 .^{\mathrm{a}}$ con relación al hallazgo del nombre de Segóbriga, se cambia súbitamente en alegría en la carta 5 . $^{\mathrm{a}}$ : «Tuve mucho gusto - dice- en que al fin se hallase en Cabeza del Griego el nombre de Segóbriga. Assí salimos de dudas, y se sabe que de allí fueron obispos Sefronio y el otro... Sea enhorabuena, y dense a Dios las gracias».

Estas palabras nos inducen a pensar que efectivamente se había encon-

Historia de España dirigida por Ramón Menéndez Pidal (t. III, p. 494) y atribuido en la p. 503 a don Isidro González Velázquez, procede con casi seguridad de Tomás Fernández, como se deduce de alguno similar incluido en nuestro folleto.

La transcripción e ilustración de Cornide (Noticia de las antigüedades... Lám. 9) ciertamente depende de Tomás Fernández, aunque la transcripción de las lápidas sepulcrales de Nigrino y Sefronio tiene alguna ligerísima variante en ambos.

La última transcripción que conozco, una vez que se completaron los seis primeros trozos de mármol interpretados en 1790 con los restantes de la lápida, es la ofrecida por FernándezGuerra, y dice así F. Sefronius tegetur tomolo antestis in isto / Quem rapuit populis mors inimica suis. / Qui merit(o?) sancta perag(ens i)n corp(ore vit)am / credetur etheriae lucis habere diem. / Hunc cause meserum, hunc querunt vota dolentum / Quos aluit (se)mper voce, manu, lacrimis. \& Quem sibi non sobitus privabit transitus iste? / Seu quonum quaeritur nunc abiisse malum? / Rec(essit) sub die XVI kal(endas) Iul(ias)/era d lxxxviii / in pace (Aureliano FERNANDEZGUERRA y ORBE o. c. 139).

21 'Impugnación al papel que con título de Munda y Cértima celtibéricas dio a luz el R. P. M. Fr. Manuel Risco... por D. Juan Francisco Martínez Falero", Memorias de la Real Academia de la Historia IV (Madrid 1805) 47. 
trado en el cerro la ansiada inscripción con el nombre de Segóbriga. Ello resulta tanto más extraño, cuanto que en las futuras discusiones sobre el tema no se menciona para nada tan importante hallazgo. Más aún, Risco puede afirmar sin rubor con aires de triunfo que no se había presentado nunca por los defensores de la identidad entre Cabeza del Griego y Segóbriga «inscripción ni testimonio de geógrafo o historiador antiguo, ni otra de aquellas pruebas que se tienen por oportunas para determinar los sitios de las poblaciones» ${ }^{22}$, cosa que don Juan Francisco Martínez Falero también reconoce cuando escribe: «Es verdad que en nuestras excavaciones de Cabeza del Griego... se tuvo la desgracia de no haber encontrado alguna de aquellas inscripciones que con toda evidencia manifestasen el nombre de la ciudad a que pertenecían tales ruinas» ${ }^{23}$.

Según esto, ¿a qué se refiere Pérez Bayer cuando afirma tan rotundamente haberse encontrado en el cerro el nombre de Segóbriga? No queda otra salida que atribuir sus palabras a una interpretación falsa -o cuando menos precipitada- de alguna inscripción encontrada por aquellas semanas. Repasando las transcritas por el boticario Tomás Fernández y las publicadas por Cornide y Hübner hay que pensar con toda probabilidad en aquella en que aparecen en un renglón las letras: GOBR ${ }^{24}$. De hecho, tanto don Bernardo Manuel como don Juan Francisco (cf. nota 9) en sus deposiciones en el proceso canónico interpretan esas letras en el mismo sentido. Pero, como dice muy bien Hübner, dichas letras pueden pertenecer igualmente a Langobrica, Tongobrica, etc., y no necesariamente a Segobrica ${ }^{25}$.

Desde la carta $5 .^{\mathrm{a}}$ de Bayer hasta la carta $6 .^{\mathrm{a}}$ transcurren casi siete meses. Es muy probable que en ese tiempo se cruzasen más misivas entre él y Tavira. De todos modos hoy no se conservan en el legajo del Archivo salmantino. No sabemos, por tanto, si siguió presente el tema SegóbrigaCabeza del Griego en esa probable correspondencia. Lo cierto es que las dos últimas cartas no tocan el tema de las excavaciones. Sin embargo ya se ha visto cómo en la carta publicada en la Historia general de Mariana, fechada en Madrid el 21-III-1792, Bayer seguía fiel a su idea de la identidad entre Cabeza del Griego y Segóbriga como si de un hecho incuestionable se tratase.

22 Manuel Risco, o. c. 333-334.

23 Juan Francisco Martinez Falero, o. c. 41.

24 Archivo diocesano de Salamanca: folleto de Tomás FERnAndez, lámina 14; José Cornide, o. c. Lám. 6, n. ${ }^{\circ}$ 26; Emilius Huebner, o. c. II, n. 3122.

25 Ibíd. 
También para Tavira era clara esa identidad, como queda bien patente en la inscripción que él mismo compuso y se colocó en 1790 en lápida de mármol sobre un arco, a la entrada del crucero de la basílica donde se descubrieron los restos de Nigrino y Sefronio. Así reza esta inscripción: ANNO REPARATAE SALUTIS MDCCLXXXX / ANTONIUS TAVIRA PRIOR UCLENSIS / EPISCOPUS CANARIENSIS DESIGNATUS / EMMANUEL BERNARDUS DE COSSIO / SAHELICENSIS PAROCHUS / JOANNES FRANCISCUS FALERO ET / VICENTIUS MARTINEZ FALERO / EJUSDEM OPPIDI NOBILES CIVES / VETUSTISSIMUM HOC SEGOBRI / GENSIUM COEMENTERIUM / BARBARORUM STRAGE COLLAPSUM / ET CONGESTIS RUDERIBUS PRORSUS / OBRUTUM / PROPRIJS IMPENSIS / EFFODIENDUM CURARUNT. [... $]^{26}$.

\section{Obispo electo de Canarias}

Las dos últimas cartas de Bayer a Tavira, aparte de lo ya mencionado sobre la última fase de la publicación de la obra sobre las monedas, tienen otro punto de interés: la elección de Tavira para obispo de Canarias. Sabrosas son las noticias que este acontecimiento singular suscita en la pluma de Bayer: la noticia del primer encuentro entre ambos allá por el año 1760, cuando Tavira acababa de abandonar el seminario de San Fulgencio de Murcia y sin duda estaba ya pensando en tomar el hábito militar de la Orden de Santiago. Para Saugnieux ese encuentro con Bayer narrado en nuestra carta $6 .^{\mathrm{a}}$ «marque en tout cas une des grandes dates de la vie de Tavira» ${ }^{27}$. Don Sebastián Rodríguez Biedma, que está también presente a ese primer encuentro entre Bayer y Tavira, era por entonces el Prior del Real Convento de Uclés y quien recibió en el mes de setiembre de 1761 la solicitud de Tavira para tomar el hábito de caballero de Santiago. El momento del primer contacto entre Tavira y Bayer coincide pues con la época de la decisión del primero de cambiar de rumbo a su vida.

Bayer expresa la esperanza de que Tavira llegue un día a ocupar la sede de su querido país valenciano, «tan desgraciado tantos años ha».

26 Copio la inscripción de José Cornide, o. c. 240. Juan de Dios DE la Rada y Fidel Fita, o. c. 129-30 cuentan cómo en su excursión arqueológica encontraron esta lápida partida y medio enterrada. Allí hacen referencia a las variantes de la que ellos vieron con la transcripción ofrecida por Cornide. En el legajo de nuestras cartas hay una hoja suelta que lleva por título el siguiente: "Ynscripción que se ha puesto en vna lápida de mármol». Curiosamente en la transcripción de este papel, de aquel tiempo, se omite la voz SEGoBrigENSIUM.

27 Joël SaugnieuX, o. c. 40. 
Expresión ésta que sin duda ha de interpretarse como un juicio negativo de los últimos prelados valencianos. También la frase «en un tiempo en que por nuestros pecados hemos visto y vemos haberse hecho de las piedras hijos de Abrahám» parece referirse a los que sin méritos habían ascendido a sedes episcopales. Por el momento nada puedo añadir sobre si tales frases pueden interpretarse a la luz de otros juicios de Bayer sobre el episcopado de su tiempo o sobre algunos prelados en concreto.

Las intrigas palaciegas, que propalan la renuncia de Tavira y la concesión de su mitra al Sr. Múzquiz ${ }^{28}$, nos sitúan a Bayer en el barroco cuarto del Patriarca aturdido por los gritos de los cortesanos y damiselas. Sin duda todo aquello no le iba al erudito valenciano, dedicado por entero a sus libros y a sus amistades de verdad.

Basten estos apuntes para una mejor comprensión de las cartas bayerianas, aunque sería desacertado resumir su valor en la temática que queda expuesta con anterioridad. Todo lector medianamente instruido descubrirá en ellas otras resonancias y valores no apuntados aquí.

\section{Las cartas de Risco y Cornide}

Como ya se dijo al principio, las cartas de Bayer iban dirigidas a Tavira prior de Uclés por los años 1788-90, mientras que éstas van dirigidas a Tavira obispo de Salamanca en el año 1801. Pero el tema sigue siendo el de los descubrimientos arqueológicos de Cabeza del Griego, tema, al que según la expresión de la carta de Cornide, Tavira sigue contemplando con «inclinación», es decir con particular interés y cariño.

Risco anuncia el día 2]-II-1801 el envío de un papel por él compuesto sobre Cabeza del Griego, refutando «las grandes equivocaciones» que se habían cometido por Cornide en el tomo $3 .^{\circ}$ de las Memorias de la Real Academia de la Historia. No he logrado localizar en el Archivo diocesano de Salamanca el escrito de Risco, pero no me cabe duda de que se trata de su Demostración (cf. nota 18).

El escrito de Risco es mucho más breve que el de Cornide, y su postura, por lo que al cerro manchego se refiere, puede sintetizarse en lo siguiente: en Cabeza del Griego no estuvo la ciudad de Segóbriga, sino la de Munda celtibérica. A ella pertenecen las ruinas romanas y góticas descu-

28 Ignoro quién es el Sr. Múzquiz. ¿Se tratará de don Miguel de Múzquit, conde de Gausa, o de algún pariente suyo? 
biertas en el cerro. Por otra parte no puede afirmarse que Nigrino y Sefronio fueran obispos segobricenses. Más bien habría que suponer que fueron obispos de Valeria.

Afirma también Risco en la carta a Tavira no haber querido imprimir su escrito contra Cornide por no desairar a un colega de la Real Academia de la Historia y, en definitiva, a la misma Academia que dio el pase a la «memoria» de su académico. De hecho su escrito vio la luz pública, primero en la Gaceta y después en el tomo XLII de la España Sagrada ${ }^{29}$. ¿Qué razones movieron a Risco a cambiar bruscamente de opinión para decidirse a publicar su «papel»? No hay por qué atribuirlo a torcidas intenciones, pero no deja de llamar la atención de haber escogido para hacerse público el tiempo de la estancia de Cornide en Portugal, donde éste se hallaba en viaje literario por comisión de la Academia ${ }^{30}$.

A la vuelta a Madrid Cornide pretende entrevistarse con Risco para informarse más directamente de las razones de su escrito, pero el agustino muere inopinadamente. La muerte de Risco ocurrió el 3-IV-1801, o sea poco más de un mes después de escribir la carta a Tavira que se publica en estas páginas. ¿Es éste el último escrito suyo conocido?

Cornide afirma en su interesante carta a Tavira que don Francisco Martínez Falero había querido parar el golpe de la publicación de Risco ${ }^{31}$,

29 Cf. nota 18. Encuentro una cierta dificultad de fechas para compaginar los distintos elementos de la historia: Cornide afirma que el escrito de Risco se publicó durante su estancia en Portugal, al igual que su propia «memoria» sobre Cabeza del Griego. Por tanto estuvo en Portugal por lo menos desde el 1799 (aparición de la «memoria») hasta 1801 (aparición del tomo XLII de España Sagrada). A la vuelta de Portugal ya compra Cornide dicho tomo y pide entrevistarse con Risco, pero lo halla «de cuerpo presente». Risco muere, como dice el Diccionario de Historia Eclesiástica de España, el 3-IV-1801 (III, 2093). ¿Es posible que entre el 21-II y el 3-IV cambie Risco de opinión y se publique su escrito, primero en la Gaceta, y después en la España Sagrada? ¿O alude la carta de Risco a Tavira a algo distinto de lo publicado?

30 El inciso «a propuesta suya» que introduce Cornide en su carta hablando de su viaje literario a Portugal resulta un tanto ambiguo: ¿Se refiere a la Academia de la Historia o a Tavira? Creo que a lo primero, pues siempre que habla de Tavira lo hace con las fórmulas $\mathrm{V}$. S. Y. ó V. Y., pero no con la fórmula «suya» o Vd.

31 Nuevamente queda la ambigüedad lingüística en las palabras de Cornide «su carta al P. Risco»: ¿carta de Tavira a Risco o de Martínez Falero a Risco? Me inclino a lo segundo por dos razones: primera, por lo dicho en la nota anterior; y segunda, porque Risco había escrito a Tavira diciendo que no iba a publicar nada contra Cornide, lo que hace suponer que no estaba al corriente de la nueva decisión de Risco, por lo que no tenía por qué escribirle sobre un asunto que desconocía. 
pero «no llegó a tiempo de suspender la publicación». Nuevo indicio de que Risco cambió precipitadamente de opinión de lo que le comunicaba a Tavira. Según se nos cuenta, Francisco Martínez Falero, también él individuo correspondiente de la Real Academia de la Historia, había hecho ciertos descubrimientos en favor de la tesis de Cornide-que era la misma de Bayer-, cosa que sorprendentemente ocurrió «en consequencia de la lectura de la Memoria del P. Risco». Con ellos pensaba que Cornide tenía argumentos suficientes para rebatirle. No se decidió a hacerlo por el momento, limitándose a remitir a Falero diversos apuntes del P. de la Higuera, Donio y Muratori, mientras investigaba más el asunto.

El amigo de que habla Cornide como intermediario a fin de averiguar la veracidad de la inscripción de Cartama es sin duda el propio Juan Francisco Martínez Falero, a juzgar por lo que él mismo dice en su Impugnación ${ }^{32}$. De hecho Cornide no llegó, que yo sepa, a responder a Risco. Sí lo hizo, sin embargo, Martínez Falero. Su Impugnación, que deja traslucir las cualidades jurídicas de su autor (alguien llamó después a su trabajo «discurso forense»), tiene un cierto parentesco con su deposición en el proceso de 1790-92. Por la carta de Cornide sabemos que Martínez Falero había ya compuesto parte de su trabajo a finales de 1801 . Y no se equivocó en su apreciación de que aún tardaría tiempo en publicarlo, pues se publicó en 1805.

Nada conozco de la correspondencia de Tavira con Martínez Falero nombrada en la carta de Cornide, como tampoco de la respuesta de Tavira a Cornide. Los colegios «bajo la dirección» de Tavira son sin duda los Colegios mayores salmantinos ${ }^{33}$.

32 C. Juan Francisco Martinez Falero, o. c. p. 38, nota 1.

33 Los cuatro colegios mayores salmantinos fueron reformados por el obispo Bertrán, aunque el alma de la reforma fue Bayer. Tavira, por la relación con ambos, siguió muy de cerca el asunto. Dos noticias del año 1799 he encontrado en el Archivo diocesano de Salamanca que dan competencias a Tavira sobre estos colegios. Primero se conserva un "Inventario de la Librería del Colegio del Arzobispo de la Ciudad de Salamanca con arreglo a los Estantes y Caxones hecho de orden del Yllmo. S. ${ }^{\circ r} \mathrm{D}^{\mathrm{n}}$. Antonio Tavira y Almazán del Consejo de S. M. obispo de esta Diócesi, comisionado por la Superioridad para entregarse (enterarse?) de esta librería, formado en el mes de Enero del año de 1799". ¿Estaba enterado Cornide de que Tavira se ocupaba de las librerías de los colegios? Se conserva también una carta del Marqués de la Granja a Tavira de fecha 15-III-1799, en la que le indica las normas a seguir una vez que se ha efectuado la tasación de las fincas de los colegios. Se indica que Tavira contestó al día siguiente. También son conocidas las intervenciones de Tavira en el colegio de los Irlandeses de Salamanca, aunque no es de pensar que en su librería hubiera nada relacionado con el P. de la Higuera, que es lo que interesaha a Cornide. 


\section{Datos complementarios}

En el mismo legajo del Archivo diocesano de Salamanca que ha ocupado estas páginas hay todavía otro material sobre los descubrimientos de Cabeza del Griego. Sin pretender una recensión completa del mismo, sí quiero referirme todavía a tres documentos:

$\left.1 .^{\circ}\right)$ Un largo juicio en latín no firmado sobre las excavaciones, con referencia especial a las virtudes de los obispos Nigrino y Sefronio. Escrito en 1790 como se deduce del contexto. Incipit: Donec a peritioribus antiquitatis... Explicit:... eorum cultum augurantes. Supongo se tratará del trabajo del mercedario Fray Ramón Martínez Falero (hermano de don Juan Francisco) mencionado por Cornide ${ }^{34}$.

2. ${ }^{\circ}$ Carta de Canga Args (Argüelles?) a don Ignacio López Ansó, fechada en Zaragoza a 20 de Febrero de 1790. Entre otros temas de la carta, resaltan su elogio de Tavira y las respuestas sobre la interpretación de algunas inscripciones descubiertas en Cabeza del Griego y de algunas de sus iniciales: en concreto de la inscripción de la Memoria de Cornide Lám. 5. ${ }^{a}$, $n .^{\circ} 6$ y de las iniciales $D . S$. C. de la $L a ́ m .5 .^{a}, n .^{\circ} 4$ y de las iniciales $D . M$. $S$. de la Lám. $5 .^{a}, n .^{\circ} 13$. Sobre la rectitud de las interpretaciones de Canga, puede consultarse Hübner en el lugar citado. Canga adjunta además mapas y otro material referido a Cabeza del Griego.

$\left.3 .^{\circ}\right)$ Copia de una carta de don Pedro Escolano de Arrieta a don Juan Francisco Martínez Falero, fechada en Madrid a 11 de Junio 1790. Le comunica los trámites que se han hecho en la Corte sobre su solicitud de construir una tapia de protección en torno a las excavaciones de Cabeza del Griego y la decisión final del Consejo de construirla del caudal de los propios de Saelices. Se nombra además a Martínez Falero encargado de la obra. Una carta complementaria a ésta la publica Cornide ${ }^{35}$.

La inscripción latina correspondiente a la nota 26 hace también alusión, en la parte no transcrita en este trabajo, a que Carlos III mandó rodear las excavaciones de un muro a expensas de los ingresos públicos. Por su parte don Juan Francisco Martínez Falero colocó otra extensa inscripción, ésta en romance, a la entrada de la cerca ${ }^{36}$. La excursión arqueológica de De la

34 Cf. José Cornide, o. c. 213.

35 Ibíd. 242.

36 Ibíd. 241. 
Rada y Fita encuentra todavía esta cerca de protección, pero ya había desaparecido la inscripción fijada por Martínez Falero ${ }^{37}$.

\section{Transcripción de los textos}

Se respeta en la transcripción la grafía arcaica, modernizando tan sólo la acentuación y la puntuación. Se conservan sin desarrollar las abreviaturas de tratamiento y cortesía ( ${ }^{\circ r}$., D., VM., II ${ }^{\mathrm{mo}}$, V. S. Il ${ }^{\mathrm{ma}}$., Blm., etc.).

\section{Benigno Hernández, S. J.}

\section{TEXTOS}

\section{1. ${ }^{a} \quad$ PEREZ BAYER A ANTONIO TAVIRA}

Madrid a 28 de Octubre 1788

$\mathrm{S}^{r}$. Prior, dueño y amigo estimadísimo: Por todas partes me rodea VM. y deja de cada día más obligado. Luego que llegué a ésta (fue a Dios gracias el día siguiente a nuestra despedida y con toda felicidad) vino a favorecerme con su visita de parte de VM. y esse Real Convento un señor de su hábito y conventual; luego el amigo y Sr. D. Pedro, su hermano; y hoi me hallo con la mui estimada de VM. y las dos notas de las obras de Córdova y el Anónymo. Todo es cargarme VM. y essa Real Casa de obligaciones a que yo me reconozen con mui corto caudal para corresponder; pero me consuelo con que VM. y essos $\mathrm{S}^{\text {res }}$. se pagarán de mis buenos deseos y voluntad de servirles. Ya dudo si la obra de Córdova tendrá lugar en la Biblioteca, por la estrechez del tiempo: ya a lo que hai ponen los impressores mil dificultades (esto yo ya entiendo que es para que se les duplique al fin de la obra la gratificación), pero es preciso decirles que tienen razón, que es preciso trabajar algo más y sobrellevarles. El otro Anónymo puede tener mérito, pero en el prólogo digo que omito a los Anónymos de que D. Nicolás Antonio no hizo mención, a excepción de los que por otro indicio o señal no son conocidos. De quien daré a VM. buenas y seguras noticias presto queriendo Dios es de D. Martín Pérez de Ayala: son nuevas, novíssimas impressas en Lovaina el año passado de 87: voi acopiando libros para mi Biblioteca de Valencia. Ya he embiado allá dos cajones y preparo seis para el viage del ordinario próximo. Repito a VM. y a esos $\mathrm{S}^{\text {res }}$. mi fiel afecto y gratitud y ruego a nuestro $S$.' que guarde su vida años.

Blm. a VM. su muy afecto recordado amigo servidor y capellan

Francisco Pérez Bayer

Sr. Dn. Antonio Tavira

Prior de la Real Casa y Convento de Vclés, etc.

37 Juan de Dios De La RaDA-Fidel Fita, o. c. 129. 


\section{2. ${ }^{a}$ PEREZ BAYER A ANTONIO TAVIRA}

Madrid 18 de Diciembre 1789

Muy ilustre $S^{r}$. Prior y mui dueño mio: Convalenciente y no aun reparado del tudı de cinco semanas de cama con vehementes dolores de riñones y estómago y una destilación fuerte al pecho, que se temió degenerasse en pulmonía, recibo la mui estimable de VM. de 16 , y no puedo explicar el gozo que tengo en ver su letra, que manifiesta su buena salud -Dios se la conserve muchos años para su maior servicio y gloria- y assimismo por las noticias tan plausibles y seguras de essos insignes descubrimientos en Cabeza del Griego. Sea mil vezes enhorabuena, y que se atribuya a VM. esta gloria. Yo, desde que vi por la vez primera la inscripción en Sahelizes en casa del $\mathrm{S}^{\mathrm{r}}$. Martinez Falero, me convenci, y a más a la vista del sitio donde se halló, de que allí se ocultaban monumentos mui conducentes a nuestra Historia Ecclesiástica y Geografía; y acaso me huviera anticipado a hacer alguna excavación. Pero, amigo, las necessidades presentes, digo las que se tienen siempre a la vista, egecutan más. Por de contado la memoria de los dos Santos Obispos es apreciabilíssima, y lı será más, si se va descubriendo, como yo espero, y que se logre una cabal ilustración histórica y geográfica. Bueno fuera se hallase el nombre de Segobrica: pero para mi está ya bastantemente descubierto en la piedra de casa del $\mathrm{S}^{\prime}$. D. Vicente Martínez en el pedacito más chico de los tres de que consta, el qual debe guardarse como oro, y assí lo encargué yo a dicho Señor, a quien pondré también dos letras en respuesta de lo que me escribe. Acaso el $\mathrm{S}^{r}$. Conde de Floridablanca me hará saber algo de lo que VM. le escribe. Justamente es hoi el correo más fuerte del año: ¿quánto me dilataría yo si no fuesse por esta razón? ¿Y qué? ¿Me detendría nadie, que no passasse aí y allá luego? Estoi aún débil, y la cabeza como hueca. Trabajo mui poco en limar mi nuevo trabajo De numis Hebr. Samar. adversus Tychsenium, etc. Si no demuestro matemáticamente su autenticidad, pierdo la causa. El Tychsen no lo entiende absolutamente. Pero esto es poco, es un gran canalla, y aún más los que le han inducido de acá. Va a imprimirse y se dedicará a nuestra común madre la Vniversidad de Salamanca. Me esfuerzo a escribir y quisiera dilatarme. Espero la continuación de noticias, y siempre las de la buena salud y felicidad en las próximas Pascuas del nacimiento de nuestro Redentor y siguientes y siempre, y los estimables preceptos de VM., y aún más para gloria del Señor y bien de la Nación. Y a Dios.

M. I. Señor: B. L. M. de Vm. su fiel y verdadero amigo y capellán in Domino

Francisco Pérez Bayer

M. I. S'. D. Antonio Tavira

Prior de Vclés.

\section{3. ${ }^{4}$ PEREZ BAYER A ANTONIO TAVIRA}

\section{I. S'. Prior}

Dueño y amigo estimadísimo: Quando me trageron esta mañana la estimada última de Vm. estaba conmigo el P. M. Risco: leímosla y con este motivo se leyeron las antecedentes de VM. y del $S^{r}$. Falero, y las inscripciones antigua y moderna de Sepronio y Nigrino. Nada sabía y tuvo mucho gusto; y como tenía el P. Maestro algo de prisa, se lo confié todo y lo llevó para hacer sus reflexiones. Yo sí tengo copia exacta de la antigua inscripción de Sepronio o Sefronio, y hago memoria de que es muy diferente de la que vm. me embía: porque la original tiene tres trozos, y en el más pequeño de ellos, que se ingiere entre los dos grandes que VM. 
demuestra en su copia, se lee, si bien me acuerdo, COBR., parte de Secobrica. Por esta razón, quando yo la vi la primera vez, encargué mucho al $\mathrm{S}^{\mathrm{r}}$. Falero que guardasse mucho aquel pedazito, y ahora nuevamente se lo repetí. También hoi me escribe que asta ahora no hai novedad. No puede responderle, porque, gracias a Dios, no falta en qué entretenernos. Vamos ya con Tychsen a vueltas. Habla este hombre a vulto, sin entenderlo: ita me Deus amet! De Estado nada se me ha dicho asta ahora: tal vez entre tantos assumtos como dicen se tratan, se descuidará de esto. Et bene vale, mei memor!.

De VM. de corazón amigo, siervo y capellán Q. S. M. B.

Francisco Pérez Bayer

Yo buscaré mi copia y la enviaré a VM.

S'. D. Antonio Tavira

Prior del Real Convento de Velés.

\section{4. ${ }^{\text {a }}$ PEREZ BAYER A ANTONIO TAVIRA}

\section{Madrid 8 de Enero de 1790}

$\mathrm{S}^{r}$. Prior mi estimado dueño: Mucho gusto recibí con la de VM. de 6, en que venía copia de la inscripción de Sefronio, tan aumentada respeto de la que yo vi original en casa del $\mathrm{S}^{r}$. Falero en Sahelizes. Sea muchas vezes enhorabuena. Gran pérdida es la del pedacillo de la piedra original, que yo copié allí mismo con el maior cuidado, en que seguramente lo estoi mui engañado) vi estas letras OBR o otras que podían hacer al nombre de Segobrica. Y ahora, visto el todo de la inscripción, no hallo dónde poderlas acomodar, sino que sean las últimas del pedazo $2 .^{\circ}$ que comienza $\mathrm{S} \overline{\mathrm{ANC}}$, es a saber 'OBI. Yo he buscado mi copia, y no acierto dónde la he puesto. Seguramente me vendrá a la mano y la embiaré a VM. tal qual. El verso Qui mer... acaso fluiría bien assí.

Qui meruit sanctam peragens in corpore vitam y parece que la quarta letra del MER' inclina más a V. que a I., bien que no ata mucho con el CREDETUR que sigue.

El verso que comienza Quem sibi \& y siguiente necessitan de Edipo: el sobili por 'OBI no me acomoda demasiado; sí el Transitus iste. Acaso: non sobito pro subito, como arriba tomolo pro tumulo. El quaeritur, aunque con diphtongo, paréceme que es queritur de queror: antes el querunt de quaero sin diphtongo. Translúcese que el sentido del dísticho sea que su muerte o tránsito, no súbito sino premeditado, no fue malo para él, sino para los miserables y dolientes o enfermos a quienes alimentó y ayudó con su predicación y sus limosnas.

Los VIII. es el final de la ERA. ¿Quiera Dios se descubra toda y darnos esta satisfacción! Es monumento digníssimo y tiene poco de bárbaro para el siglo que indica su carácter, que puede ser del octavo al principio o fines del séptimo. No me han dicho asta ahora nada de arriba. Siempre escribo de prisa: todo lo verá el P. M. Risco. Estoi lleno de quehacer y vamos ya con mi Auctario. Soy de VM. siempre y por siempre de boníssima voluntad, y a Dios.

M. I. $\mathrm{S}^{\mathrm{r}}$. Prior

De VM. ex animo Francisco Pérez Bayer

Sr. D. Antonio Tavira, mi dueño. 
PS. En la copia que me embía el $\mathrm{S}^{r}$. Falero, el verso Quem sibi sigue: NO SOBI. Acaso Nos obitus; pero como luego dice transitus, es mui difícil de acomodar. No sé qué diga a VM., sino que soi suyo de corazón.

Seguramente las letras OBI... no pertenecen a SEGOBRICA, cuya voz no cabe en el verso. Temo que con estas ocurrencias mías, o bien sean extravagancias, pervierta yo el buen juicio de VM.

\section{5. ${ }^{\mathrm{a}}$ PEREZ BAYER A ANTONIO TAVIRA}

Madrid 6 de Abril 1790

M. I. Señor Pior

Amigo y S'. D. Antonio: Dias ha que estoi con VM. en deuda. Seguramente he querido corresponder, pero han ocurrido ciertos disgustillos que aseguro a VM. que me han quitado la gana para todo lo bueno. Deseo que lo esté VM. como yo lo estoi, a Dios gracias, aunque siempre las piernas flojas. Ahora pienso hacer por las mañanas unas saliditas y dar algún passo ayudado de un bastón (pues veo que también lo llevan los jóvenes y aún los niños por moda, y assí no me costará vergüenza).

Tuve mucho gusto en que al fin se hallasse en Cabeza del Griego el nombre de Segobriga. Assí salimos de dudas, y se sabe que de allí fueron obispos Sefronio y el otro, y hai campo para buscar sus nombres en los Códices Vigiliano y Albeldense. Pro sólo esto puede VM. dar por bien empleado su trabajo y el coste, con que de camino habrá VM. socorrido muchas miserias. ¿Y qué? ¿Ha de quedar aí? Pues, ¿no averiguaré VM. quiénes fueron essos obispos, puesto que despiden sus inscripciones tan buen olor de santidad? Mui del caso es que sus huesos o cenizas se conserven en lugar distinguido. Sea enhorabuena, y dense a Dios las gracias.

Se comenzó ya a imprimir mi Auctario o Vindicias: formará un tomo igual al antecedente, y lo será en letra, papel y adornos. Mi ánimo fue dedicarlo a nuestra común madre la Vniversidad de Salamanca, quando creí sería sólo un quaderno de 15 ó 20 pliegos, y que se podría unir a lo primero; pero siendo ya un libro que puede andar por sí solo, fuera reparable que no se dedicasse al Soberano, como el primero a su Augusto Padre b. m. He pedido la licencia para la dedicatoria: aún no ha bajado. Veremos. La obra-creo- está trabajada con pulso: a lo menos he puesto en ella el cuidado possible. A nadie temo más que a mí mismo, porque allí erramos más donde menos creíamos que se puede errar.

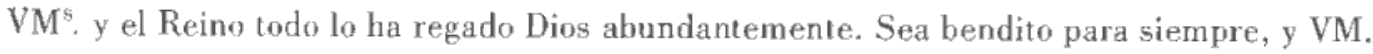
vea qué manda, quia audit servus tuus

Perezius Bayerius

M. I. Sr. Prior D. Antonio Tavira.

\section{PEREZ BAYER A ANTONIO TAVIRA}

Madrid 28 de Octubre 1790

III $^{\text {tno }}$. Señor

Dueño y amigo estimadísimo: Ya comenzamos a ver cumplida la profecía del $S$. D. Sebastián Rodríguez Biedma, que goze de Dios. Tal como sucede, me lo dijo en casa de D. 
Pedro Marentes (calle de las Carretas) havrá treinta años, donde tuve el honor de conocer a VM. la vez primera: «Le verá VM. mitrado». Sea, amigo $\mathrm{Il}^{\mathrm{m}}$. Señor, para maior gloria de Dios, bien de VM., de su familia y del Estado, en un tiempo en que por nuestros pecados hemos visto y vemos haberse hecho de las piedras hijos de Abrahám. Le quisiéramos a VM., es verdad, más cerca; pero la mano que hoi se extiende, mañana se recogerá y recogerá a VM. ¡Ojalá azia mi país, tan desgraciado tantos años ha! Demos a Dios las gracias, y vm. reciba de mi fiel amor y gratitud las mas cordiales enhorabuenas. No he passado a darlas al S'. D. Pedro y su casa, porque haze días que apenas salgo de la mía y creo que estén en el Sitio estos $S^{\text {res. }}$. Me hacen impressión los fríos. En casa he trabajado en concluir y corregir la obra e impressión de mis Vindicias numor. Hebr. Samaritanor. contra Tychsen y otros. Se están ya enquadernando y espero se presenten el 7 u 8 de Noviembre a S. M. que ha tenido la dignación de admitir la dedicatoria: llevan su Real Retrato a la frente y varias láminas. Impressión, esto es, letra, papel y tomo, igual al antecedente del mismo assumto. Oportunamente $\mathrm{M}^{\mathrm{r}}$. Barthelemy, primer antiquario del Rey de Francia, de suyo, y sin saber yo nada, ha publicado una Retractación de su antiguo modo de pensar acerca de ciertas monedas que tuvo por de Jonathán, hermano maior de Simón Macabeo, y de la versión latina de la famosa inscripción fenicia de Malta. De ambas confiessa que se engañó (¡vea VM. el carácter de un verdadero sabio!) y que Bayer tuvo razón en impugnarle sobre el primer punto, y que fue feliz en la interpretación de la inscripción sobredicha, la que luego que vió, la adoptó inmediatamente. Esto son bagatelas. Espero me dará S. M. licencia para passar lo recio del hibierno en mi país: no está esse camino (que llaman ael corto») hoi tratable por las lluvias. Deseo que Nuestro Señor conceda a VM. verbo et exemplo populis quibus praeest (Yo añado: et praeerit) proficere, ut ad vitam una cum grege sibi credito perveniat sempiternam. Ac bene vale, mei memor.

$\mathrm{Ill}^{\mathrm{InO}} \cdot \mathrm{S}^{\mathrm{r}}$.

B. L. M. de VS Ill ma su fiel amigo y muy recordado servidor y capellán

Francisco Pérez Bayer

Ill $^{\text {mo }}$. Sr. D. Antonio Tavira

Prior de Vclés. electo de Canarias.

\section{7. ${ }^{\circ}$ PEREZ BAYER A ANTONIO TAVIRA}

Madrid 12 de Noviembre 1790

Ill ${ }^{\text {mº }}$. Señor

Dueño y amigo estimadísimo: Acabo de recibir la de VM. He derramado sobre ella algunas lágrimas. Adoremos la Providencia del S'. Yo en el Sitio, de donde vine antes de anoche, dí la enhorabuena al $S^{r}$. Múzquiz de el Obispado de VM., porque me aseguraron que VM. había renunciado y se le hıbían dado de rechazo. El caso es que me pareció que la había admitido, y al despedirme le repetí: “Dios dé a VM. acierto». Era en el quarto del Patriarca, y había tanta bulla, que ni él a mí ni yo a él nos entendimos. El assumto es que Dios va encaminando a VM. para servirle, y no quiere que essa luz esté sub modio. Sea bendito para siempre. iAssí se proporcionasse lo que VM. fácilmente adivinará que podría desear yo! Presenté mi obra: fue bien recibida de aquellos $\mathrm{S}^{r e s}$. Me honraron sin término. Luego que se enquaderne (lo estará para el lunes 15), se embiará un egemplar a casa del $S^{r}$. D. Pedro. Marcho mañana a Valencia y ocurre infinito. El camino de Sahelizes no está en hibierno para coches. Escribame VM. allá y mándeme con toda satisfacción. Ya sabe mi obligación y mi verdadero y antiguo afecto sine 
fuco \& fallaciis. Dígame VM., dejando aparte nuestro afecto: ¿qué juicio hace de mi obra? Más estimaré su censura, sea o no favorable, que el volo de más de quatro que ya la han hecho de bolín de bolán; pero está en concepto de que son censores natos. Dios me libre de tal classe de gentes. Si ellos entraran en el palenque, iqué miserias no viéramos!

A Dios, mi estimadíssimo dueño y amigo; y Dios nuestro $\mathrm{S}^{r}$. prospere y guarde a VM. in viam pacis Amén.

III $I^{\text {mo }}$. $S^{r}$.

$\mathrm{B} l \mathrm{~m}$. de $\mathrm{Vm}$ su fiel, constante y antiguo amigo, servidor y capellán

Francisco Pérez Bayer

$\mathrm{Ill}^{\mathrm{mo}}$. $\mathrm{S}^{r}$. D. Antonio Tavira mi $\mathrm{S}^{\prime}$.

\section{8. ${ }^{\text {a }}$ FRAY MANUEL RISCO A ANTONIO TAVIRA}

Madrid 21 de Febrero de 1801

Il ${ }^{\text {rno }}$. Señor: Remito a V. S. Il ma mi papel de la Cabeza del Griego, para que sirva de algún desahogo entre las graves ocupaciones del ministerio pastoral. Nada tengo que añadir a lo que él dice y sólo debo exponer que, teniendo muchas y excelentes reflexiones que convencen las grandes equivocaciones que se han publicado en la Memoria del mismo Cerro por la Academia de la Historia, he omitido su impresión por no confundir al autor y a los que aprovaron su escrito.

Viva V. S. Ima persuadido de mi profundo respeto y fino amor y crea que es y será siempre el más atento y apasionado servidor y capellán de V. S. $\mathrm{Il}^{\mathrm{ma}}$.

Fr. Manuel Risco

\section{9. ${ }^{a}$ JOSE CORNIDE A ANTONIO TAVIRA}

Yll $^{\text {mo }}$. Señor.

Muy $\mathrm{S}^{\circ}$. mío y de mi mayor respeto: Como yo sé la inclinación con que V.S.Y. mira las ruinas de Cabeza del Griego, cuyo descubrimiento se debe a las fatigas y cuidado de V. Ya., creo que no le incomodaré en solicitar los medios de conservarlas en la posición en que procuré ponerlas por medio de la Memoria impresa en el Tomo $3 .^{\circ}$ de las de nuestra Real Academia de la Historia; a este cuerpo dejé confiado su original quando la Corte lubo a bien, a propucsta suya, destinarme para hacer un viage literario en el Reyno de Purtugal, y durante mi ausencia halló conveniente la Academia hacerla pública por medio de la prensa.

Durante la misma, y hallándome en Lisboa, he visto publicada en la Gaceta una Memoria o Discurso de nuestro compañero el Pe: Maestro Risco impugnando mi modo de opinar quanto a la situación de las ciudades de Munda y Certima ${ }^{1}$, que fundado en la ynscripción publicada por el Maestro Flórez (como existente cerca de Cartama) quise reducir a la Andalucía; por

1 Cf. José Cornide, o. c. 125-30.

z Cf. Enrique FloreZ, España Sagrada XII (Madrid 1754) 291. 
entunces ni pedi dicha Memoria a España ri me cuidé do verta, reserbándolo para quanto me restituyese a Madrid: y en efecton, a pocos dias de mi arribo, conprando el Tomo 42 de la

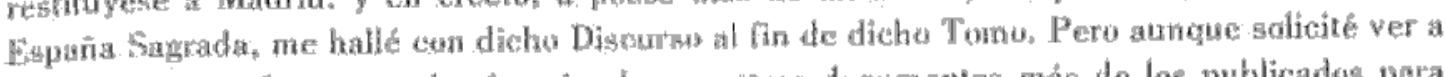
su autor para informarme de sí tenia alguars otros documentos más de los publicados para remover a Segubriga de Cabcza del Griego, lube el sentimiento de hall harto de cuerpo presente.

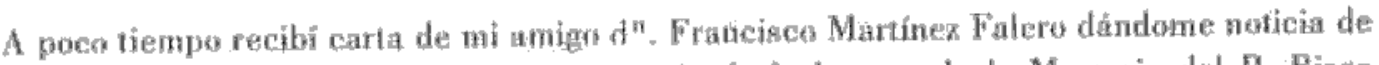
los nuebas descubrimienton que en consequencia de la lectura de la Memoria del P. Risco había hecho y excitándome a que en cuxisequencia de ellor proetorase rebalizle; pero yo cref que nu debia salir al público antes de verificar por mí mismo lo que me referfa Falero, y me contenté con enviarle copia de parios apuntamientos que conserbaba del Pe. Higuera ${ }^{3}$ y de las ynacripciones y sus lítulos publicadas por Risea, y verificadas en las obras de Donio y Muratorit y ul mismo tiempo me vali de un amigo para que escriviese a Cartams a fin de que me dijesen si alli cerca hatia harmita con titulo de Noestra $S^{\text {th }}$. de la Guerra o de la Huerta y si en ella se hallaba la inseripción publicada por llorez conko tomada de el Thesoro de Muratori.

Luego que recibí respuesta de Cartama asegurândome que no hulbía alli semejante hermita y que tampoco halia entre las muchas inscripciones que se hallaban en la Villa quten en ella supiese descubrir la gue cituba Forrez. me determiné a emprender un nuebo viage a Cabeza del Griego, y aus tube por conveniente extenderk hasta el Reyno de Aragón para ver et nacimiento del Tajo, la Muda de $\mathrm{S}^{n}$. Juan, a donde el $\mathrm{S}^{\text {tor. Traggia quiso llebarse a Segúbriga }}{ }^{6}$, y la ciudad de Albarracín, en que también sonspecha el abate Masdeu pudo haber eatador? y bolviéndome por Moya, la Minglanilla y otres pueblas de la Mancha aita, vine a contirontar las raticias que me habia dado Falero, que hallé exactan; aquel amigo me mostrố en su teasa la correapondencia eon V.S.Y. y su carta a el P. líiscu, que no llegó a tiempo de suapender la publicación de mu Memeris, comunicátidome to que Ienia adelantado para rebatirfa, que me pareció bien trabajado y convincente. No obstante, como yo veo que aún tardará en ponerko en essado de publicarlo o de presentarlo a la Academia, y como por otra parte me creo obligado con êsta a confesar en la que me he engañado y lo que no ha gabido el Magsiro Risco, informado for la correspondencia de V.S.Y. con Folero de que en las librerías de esos Colegios que se hallan bajo la direceín de V.S.Y. había algunos papeles de Higuera que pueden

3 Se trata del P. Jerónimo Román de la Higuera, S. J., citado abundantemente en los trabajos de Cornide, Risco y Martínez Falero mencionados en las páginas anteriores. Sobre las obras de Román de la Higuera ef. Bibliothèque de la Compagnie de Jésus. Ed. por Carlos SOMMERvoGEL t. IV (Bruxelles-Paris 1893 = Louvain 1960) 369-75.

a Se refiere a las de dos columnas miliarias recogidas primero por Juan Bautista Donio (hechas públicas en 1731 por Antonio Francisco Gorio) y copiadas nuevamente por Muratori. Las reproduce Risco en España Sagrada XLII (Madrid 1801) 343 y 345.

5 Cf. Enrique Florez, España Sagrada XII (Madrid 1754) 291-92. Flórez habla de la "Ermita de nuestra Señora de la Guerta» (p. 292). Ni Flórez ni Risco se refieren a nuestra Señora «de la Guerra». Es Juan Francisco Martínez Falero (cf. o. c. 11, 12, 24, etc.) el que lee así a Flórez.

8 Cf. Joaquín Traggia, Aparato a la historia eclesiástica de Aragón II (Madrid 1792) art. 24 y 25 .

7 Cf. Juan Francisco MASDEU, o. c., t. XVII, Suplemento XVII, especialmente, pp. 367-74. 
conducir a nuestro asunto, recurro a V.S.Y, a quien suplico se sirva comunicarme no sólo una copia de ellos, sino de lo que convenga a la mayor claridad de un asunto en que nos interesamos los que lo habernos tratado, tanto como el público que tiene derecho a que no se le engañe.

V.S.Y. tenga a bien esta súplica mía y disponga de la respetuosa disposición en que quedo de complacerle.

Nuestro Sor. guarde a V.S.Y. muchos años, Madrid 29 de Diciembre de 1801. Ylimo. Señor. Blmo, de V.S.Y. su más atento servidor.

Joseph Cornide

Ylmo.$S^{\circ} \cdot d^{n}$ Antonio Tavira Obispo de Salamanca. 